\title{
Translating Jennifer's Story
}

\section{Louise Blacksmith Mistissini, Québec}

Hard as it was to read about Jennifer's journey, it reminded me how heart wrenching it is to go through life when you feel so alone, not knowing what to do and where to get help. I felt connected to Jennifer because I experienced some difficult times in my own life. Not the same difficulties, but the feeling of rejection, loneliness, and pain was as real as hers.

I remember when the nurse told me I had diabetes. I was devastated and I didn't want to believe it. In fact, when the doctor came in he wanted to shake my hand and said, with a smirk on his face, "Welcome to the club!" I felt so insulted that I pushed his outstretched hand away. I told him in an angry tone that I was not joining his club! I was going to fight this as best as I could and be healthy!

I was very emotional as I translated Jennifer's story. I felt compassion for her when she talked about her weight and how her boyfriend treated her. I felt her pain and frustration having to deal with confusion, uncertainty, stress, and feeling rejected and unloved. She had a lot on her plate. Her weight, drinking, drugs, her boyfriend leaving her and their four children and then to be told she was diabetic.

When she finally began to step up and help herself, I found myself cheering her on! Slowly but surely, one by one, the challenges she faced every day diminished. I was so proud when she decided to take charge of her life, that she had no desire to go back to her old way of living. Jennifer shows what a person can do when they put their mind to it. She put her past behind her and moved on with hope for a better future, free of drugs, alcohol, and food addictions. It was especially amazing to me that she no longer needed diabetes medication at all because she was careful with her diet and walking was a big factor!

Well done, Jennifer. May you continue to walk on your journey towards wellness with determination and pride. Thank you for sharing your story with us. It was an honour for me to translate it into our Cree language (James Bay Southern East Cree). 